\title{
Pesquisa e Serviço Social: da concepção burguesa de ciências sociais à perspectiva ontológica
}

\author{
Ricardo Lara \\ Curso de Serviço Social da Universidade de Uberaba (UNIUBE) \\ Centro Universitário da Fundação Educacional Guaxupé \\ (UNIFEG)
}

\section{Pesquisa e Serviço Social: da concepção burguesa de ciências sociais à perspectiva ontológica}

Resumo: Este artigo tem como objetivos questionar a concepção burguesa de ciências sociais, apresentar um breve histórico da pesquisa em Serviço Social e expor os primeiros passos da 'perspectiva ontológica' enquanto referência teórico-metodológica, com enfoque na produção do conhecimento no mundo acadêmico atual. As considerações alertam que a pesquisa e o esclarecimento teórico para os assistentes sociais, na atual conjuntura, tornaram-se seus principais meios de trabalho, pois é a partir da sistematização da realidade social que o profissional tem condições de agir com mais segurança e dar possíveis respostas que sejam aceitas pela objetividade social. O ponto de partida é situar o Serviço Social como profissão que vem assegurando o seu espaço no âmbito da pesquisa, principalmente, no que diz respeito aos estudos sobre as expressões da questão social. Destarte, acredita-se que os objetos de investigação do Serviço Social emergem de uma realidade concreta e estabelecem suas mediações numa sociedade que se produz e reproduz por meio de contradições inconciliáveis.

Palavras-chave: ciências sociais, Serviço Social, pesquisa, produção do conhecimento, perspectiva ontológica.

\section{Research and Social Work: From the Bourgeois to the Ontologic Perspective of Social Science}

Abstract: The purpose of this article is to question the bourgeois concept of social sciences, to present a brief history of research in Social Work and to present the first steps of the 'ontologic perspective' as a theoretical-methodological reference, with a focus on the production of knowledge in the current academic world. The considerations warn that research and theoretical clarification for social assistants in the current situation become their principal means of work, because it is from the systematization of the social reality that the professional has the ability to act with greater security and to give possible responses that would be accepted by the social objectivity. The study begins by locating Social Work as a profession that has been guaranteeing its space in the realm of research, principally in relation to studies about expressions of social issues. Thus, it maintains that the objects of social science research emerge from a concrete reality and establish their mediations in a society that produces and reproduces by means of unreconcilable contradictions. Key words: social sciences, Social Work, research, production of knowledge, ontological perspective. 


\section{Introdução}

A questão de saber se cabe ao pensamento humano uma verdade objetiva não é uma questão teórica, mas prática. É na práxis que o homem deve demonstrar a verdade, isto é, a realidade e o poder, o caráter terreno de seu pensamento. A disputa sobre a realidade ou não-realidade do pensamento isolado da práxis - é uma questão puramente escolástica. Marx, 1999, p. 12

O Serviço Social contemporâneo responde por uma significativa produção de conhecimentos nas mais diversas áreas e subáreas das ciências sociais. A partir dos anos de 1980, com maior evidência, a profissão se inseriu como interlocutora das demais áreas do conhecimento e começou a responder pela sua própria produção teórica, permitindo maior destaque à pesquisa acadêmica.

A pesquisa que, necessariamente, gera a produção do conhecimento tornou-se pré-requisito ao assistente social, sendo que por meio da investigação científica, que na verdade é a sistematização de uma determinada realidade social, o profissional consegue apreender as intrincadas conexões do real e, assim, construir um caminho mais seguro para aproximar-se de respostas concretas tão almejadas nas suas intervenções.

No presente texto, temos como objetivo discutir brevemente a concepção burguesa de ciências sociais, os caminhos da pesquisa e da produção do conhecimento na 'Universidade Moderna' ${ }^{1} \mathrm{e}$, ousamos apresentar os primeiros passos da 'perspectiva ontológica' enquanto referência teórico-metodológica, para apreensão e sistematização da realidade social.

\section{Prolegômenos à crítica da concepção burguesa de ciências sociais}

A pesquisa científica e suas 'metodologias' estão submetidas à concepção burguesa de ciência, a qual potencializa o desenvolvimento do conhecimento segundo a ótica do capital. O conhecimento, ou melhor, a sistematização da realidade social está voltada para interesses 'produtivos', o que torna limitada a relação do saber com o 'mundo dos homens'. Em favor desta concepção, adota-se, freqüentemente, o argumento de que a extensão da ciência moderna é sinônimo de especializações em todas as áreas do saber. O conhecimento está fragmentado e é acentuado pela falta de diálogo entre as áreas, o que, conseqüentemente, colabora para a compreensão do homem e da sociedade como partes isoladas da dinâmica social e da tecedura histórica.

Nosso intuito, neste momento, é abrir o debate sobre a fragmentação a que as ciências soci- ais foram submetidas, diante da concepção burguesa de ciência.

Segundo Lukács (1981, p. 122),

$\mathrm{O}$ fato de que as ciências sociais burguesas não consigam superar uma mesquinha especialização é uma verdade, mas as razões não são as apontadas. Não residem na vastidão da amplitude do saber humano, mas no modo e na direção de desenvolvimentos das ciências sociais modernas. A decadência da ideologia burguesa operou nelas uma intensa modificação, que não se podem mais relacionar entre si, e o estudo de uma não serve mais para promover a compreensão de outra. A especialização mesquinha tornou-se o método das ciências sociais.

As ciências sociais têm dificuldades de se afirmarem diante da ciência moderna, pela sua ineficiência em apresentar respostas práticas. $\mathrm{O}$ seu modo específico de produzir conhecimento é questionado pelo pragmatismo dos filisteus capitalistas, os quais só objetivam as ciências que buscam os resultados para o avanço das forças produtivas.

Tal questão justifica o ceticismo da ciência burguesa em relação às ciências sociais, pois a ciência positivista se contentou, em sua maioria, em conhecer o universo singular de um determinado fenômeno empírico, sem preocupações de questionar as contradições históricas que o engendram.

Quando Lukács afirma que "a especialização mesquinha tornou-se o método das ciências sociais", na verdade ele está preocupado com os caminhos das ciências sociais, mais especificamente com a influência do pensamento conservador que pretende separar e criar inúmeras áreas do saber, tais como: a sociologia ${ }^{2}$, a economia, a história.

Essas áreas correm o risco de não conseguirem comunicar-se, tornando-se estranhas entre si, apesar de terem o mesmo ponto de partida nas suas construções teóricas, ou seja, a produção e a reprodução da vida social.

A fragmentação foi criada e permaneceu no círculo acadêmico ao longo do século 20, contribuindo para o desenvolvimento da Universidade enquanto Instituição, que tem como um de seus principais objetivos formar especialistas.

Mészáros (2004, p. 291) destaca três aspectos relevantes sobre a constituição das ciências burguesas e a produção do conhecimento "no âmbito da organização e da divisão capitalista de trabalho":

- a parcialidade e a fragmentação da produção intelectual;

- as diferenças de talento e motivação, assim como uma tendência à competição a elas associadas;

- um antagonismo social historicamente específico, articulando em uma rede de complexos 
sociais hierárquicos que integram, em seu quadro, as tendências - em si e por si ainda indefinidos - dos dois primeiros, dando-lhes um sentido de acordo com suas determinações e imperativos estruturais.

O conhecimento está fragmentado pelas condições de existência das instituições de pesquisa, com destaque à Universidade, que é responsável, dentro da divisão social do trabalho, pela sistematização do saber. O conhecimento moderno, fragmentado, resume-se numa dimensão de amparo às justificativas ideológicas conservadoras. Isso é explicado pelo crescimento das ciências naturais que, necessariamente, são voltadas para interesses práticos, ou seja, suas pesquisas potencializam o desenvolvimento industrial, tecnológico e as ramificações do desenvolvimento do capital e, por conseguinte, negam radicalmente a condição do trabalho em favor da lógica do capital. Nesse processo, as ciências sociais têm dificuldades de objetivar pragmaticamente os seus estudos e são deixadas em segundo plano no âmbito científico.

Todavia, a principal questão em jogo é a seguinte: em ciências sociais, ao se realizar pesquisas e produzir conhecimentos, não se deve deixar fora da pauta as bases objetivas da sociedade que, infelizmente, têm propósitos voltados somente para a produção e reprodução da riqueza. Isto tem a ver com o "sistema do capital ser orgânico", dotado de lógica própria e de um conjunto objetivo de imperativos, que subordina a si para o melhor e para o pior, conforme as alterações das circunstâncias históricas - todas as áreas da atividade humana, desde os processos econômicos mais básicos até os domínios intelectuais e culturais mais mediados e sofisticados (MÉSZÁROS, 2004).

No entanto, uma das características das ciências sociais é edificar uma proposta que tem suas premissas no pensamento crítico, o qual põe em cheque o 'metabolismo social'. Dessa forma, o modo de sistematizar a realidade social tem que passar, necessariamente, pelo crivo da crítica, tendo por base um diagnóstico da sociedade burguesa, a qual, felizmente, não se sustenta, principalmente pelas suas 'bases objetivas de produção e distribuição da riqueza'.

\section{Pesquisa e Serviço Social - é necessário um posicionamento?}

Encontramos na Universidade um avolumado de pesquisas, que em sua maioria são exigências para a obtenção da titulação de um determinado estágio da formação profissional, mas, em alguns casos, deixam a desejar com suas construções teóricas. A pesquisa, para muitos 'acadêmicos', é o caminho mais viável para conseguirem os títulos de mestres, doutores, etc. Ao negarmos a pesquisa que visa somente os títulos, perguntamos: qual é o 'verdadeiro sentido' da pesquisa na 'Universidade Moderna'? Cremos que, em princípio, ela deveria advir da 'realidade social' com a qual os pesquisadores deparam-se no cotidiano e, num momento de indagação, começam a observá-la como movimento cognoscível.

A observação sobre a realidade social não é simplesmente um incômodo subjetivo, que apenas satisfaz a curiosidade do pesquisador; ao contrário, o ser que indaga, procura inquirir sobre 'algo' que advém da objetividade social, a qual carece do conhecimento para ser desvendada. Nas pesquisas, devemos saber fazer a pergunta, pois são as respostas que se transformam em artigos, dissertações, teses ou livros; e, se a 'pergunta' for mal formulada, o trabalho de pesquisa perderá, conseqüentemente, resplandecência.

Setubal (1995, p. 34) faz o seguinte comentário sobre a objetividade da pesquisa:

Não é raro encontrar pesquisas, sobretudo no meio acadêmico, que tratam de problemas remotos e são destituídas de interpretação mais ampla e acurada. Muitas são as que se voltam para a elaboração do conhecimento apenas como conhecimento, istoé, um conhecimento que vagueia pela realidade sem contudo dar conta dela no concretismo da sua história.

A 'humanidade social' carece de respostas ao conjunto dos 'problemas econômicos, políticos, sociais e culturais' que a assolam, pois são inúmeros, alguns de séculos, como a pobreza e outros contemporâneos, como a sexualidade, a ética e tantas outras expressões da 'questão social' 3 , que o Serviço Social, auxiliado pelas ciências sociais, objetiva investigar. $\mathrm{Na}$ investigação, os pesquisadores estudam as questões por eles enfocadas e, a partir dos 'recortes de estudo', criam as teorias para explicar determinadas realidades sociais. Na maioria dos casos, há um demasiado 'devaneio' nas teorias, nas leis, nos modelos, que se descolam do objetivo inicial da investigação e fazem da pesquisa uma abstração sem retorno ao real e, conseqüentemente, desembocam num 'estranhamento' ou misticismo do real por parte do pesquisador.

Nesse momento de total 'estranhamento' entre pesquisador e objeto de estudo é que encontramos a falta de rigor na pesquisa, pois muitos que se propõem a investigar talvez não estejam preparados o suficiente, ou não consigam visualizar a necessidade objetiva cobrada da pesquisa, que no seu caminho mais seguro objetiva desnudar o cotidiano contrastante das relações sociais da sociedade burguesa, bem como seu modo de produção e reprodução social, desencadeador das mais diversas expressões da 'questão social', que a cada nova manifestação 'dilacera' milhares de vidas ${ }^{4}$.

Sugerimos, no entanto, aos assistentes sociais que, ao indagarem sobre o real, indaguem com o objetivo 
de tratar 'a questão social' - entendida como 'deformidades' desenvolvidas no interior das relações sociais, as quais são protoformadas pela sociabilidade capitalista - na sua integridade, ou seja, estudem as expressões da 'questão social' e, posteriormente, façam o esforço de retornar o conhecimento produzido aos sujeitos envolvidos. Acreditamos, pois, que a função da ciência é desvendar o 'não-aparente', ou melhor, nas palavras de Marx: "Toda ciência seria supérflua se a essência das coisas e sua forma fenomênica coincidissem diretamente"(MARX apud LUKÁCS, 1979, p. 26).

$\mathrm{O}$ assistente social pesquisador, que objetiva o rigor teórico exigido pela ciência autêntica, deve perquirir 'as intrincadas conexões do real'. Investigar e, em consequiência, tornar cientificamente aceito o trabalho, no âmbito acadêmico, é o princípio fundamental no caminho da probidade teórica do pesquisador. Ele deve levar consigo, no percurso da pesquisa, as seguintes características: honestidade, paciência, criatividade, criticidade, audácia, humildade, diligência e, principalmente, a ética na pesquisa, para tornar-se um sujeito que indaga sobre o real, tendo por finalidade contribuir à 'humanidade social' com suas inquietações e construções teóricas, e não apenas saciar a fome voraz de títulos exigidos pela 'Universidade Moderna'.

Outro fator importante para a pesquisa, diz respeito aos 'milhões de teorias' existentes sobre um determinado assunto. Quando isso acontece, surge a necessidade do confronto de idéias que, no caso, torna-se inadiável, pois pensamentos que analisam uma mesma questão com conclusões totalmente diferentes devem ser submetidos ao diálogo para percorrerem a verdadeira explicação do assunto investigado. Não estamos aqui defendendo o pensamento único, que tanto emburrece, mas cobrando o debate que enriquece o conhecimento científico. O confronto de diferentes concepções enriquece a ciência e o que é plausível, faz cair por terra explicações equivocadas da realidade social, ou seja, falsas interpretações do "mundo dos homens'. A crítica, ${ }^{5}$ portanto, surge como uma arma certeira para desmascarar o cientificismo vulgar que paira atualmente sobre a 'Universidade Moderna'. O conhecimento crítico é a única arma que os estudiosos possuem para exigir o rigor teórico e, assim, negar definitivamente a 'pseudociência'.

Segundo Demo (1997a, p. 10),

Pesquisa pode significar condição de consciência crítica e cabe como componente necessário de toda proposta emancipatória. Para não ser mero objeto de pressões alheias, é 'mister' encarar a realidade com espírito crítico, tornando-a palco de possível construção social alternativa. Aí, já não se trata de copiar a realidade, mas de reconstruí-la conforme os nossos interesses e esperanças. É preciso 'construir a necessidade de construir novos caminhos', não receitas que tendem a destruir o desafio da construção.

No entanto, é nesse contexto de produção de conhecimentos na 'Universidade Moderna' que o Serviço Social se insere com seus programas de pós-graduação, seus núcleos de pesquisa e, por conseguinte, começa a responder por uma determinada produção científica nas mais diversas áreas do conhecimento. De acordo com Iamamoto e Carvalho (1998, p. 88), "O Serviço Social em sua trajetória não adquire o status de ciência, o que não exclui a possibilidade de o profissional produzir conhecimentos científicos, contribuindo para o acervo das ciências humanas e sociais, numa linha de articulação dinâmica entre teoria e prática". A produção de conhecimentos na área do Serviço Social acelerou a partir de 1970, momento em que iniciaram os primeiros cursos de pós-graduação na área de ciências sociais e, especificamente, em Serviço Social. Desde então, a produção bibliográfica teve um aumento considerável, sendo alimentada pelas dissertações de mestrado e teses de doutorado. Mas, foi somente a

partir dos anos de $1980^{6}$ que o Serviço Social obteve reconhecimento pelo Conselho Nacional de Desenvolvimento Científico e Tecnológico (CNPq) como uma área específica de pesquisa, sendo-lhe atribuídas as seguintes linhas de investigação: Fundamentos do Serviço Social, Serviço Social Aplicado, Serviço Social do Trabalho, Serviço Social da Educação, Serviço Social do Menor, Serviço Social da Saúde, Serviço Social da Habitação ${ }^{7}$. Atualmente, o Serviço Social integra, juntamente com as áreas de Direito, Comunicação, Economia, Administração, Arquitetura, Demografia e Economia Doméstica, a grande área de Ciências Sociais Aplicadas (KAMEYAMA, 1998).

Segundo Ammann (1984, p. 147), “A incorporação da pesquisa na prática profissional da área é um fenômeno relativamente recente, posto que tinha havido esforços orientados para consolidar uma política geral de capacitação e investigação, no campo do Serviço Social, por parte dos organismos profissionais".

Entretanto, a partir dos anos de 1980, a categoria profissional começou a contribuir e a responder pela produção de conhecimentos que dão sustentação 
segura à prática profissional. Hoje, podemos afirmar que contribuímos com significativos trabalhos de pesquisa nas mais diversas subáreas das ciências sociais ${ }^{8}$, isso se deu, principalmente, após a "renovação do Serviço Social", ou seja, ao "movimento de reconceituação", que constituiu" "[...] segmentos de vanguarda, sobretudo, mas não exclusivamente inseridos na vida acadêmica, voltados para a investigação e a pesquisa"(PAULO NETTO, 2001b, p. 136).

Contudo, tanto na intervenção quanto na formação profissional, a pesquisa é um elemento fundamental para o Serviço Social, e cabe lembrar que, para realizá-la, há exigência do aprofundamento teóricometodológico como recurso para a investigação da vida social.

A busca por referências teóricas apresenta o grande paradigma para os graduandos, mestrandos e doutorandos em Serviço Social, preocupados com as suas monografias, dissertações e teses. Em consideração a essa 'crise de paradigmas', para a qual não nos isentamos de responsabilidade, apontamos a seguir uma perspectiva teórico-metodológica de pesquisa, para a construção do conhecimento.

\section{Uma perspectiva ontológica para o Serviço So- cial}

Inúmeras perguntas surgem sobre a questão do método $^{10}$ e da metodologia; em todas as pesquisas acadêmicas há exigência pela metodologia, que na ciência moderna se manifesta como o "caminho seguro' no desenvolvimento do estudo. Na nossa compreensão o método - questão central da pesquisa comprometida - é um modo de apreensão do real, que tem por base uma concepção de mundo, na qual o pesquisador se apóia para investigar determinada realidade social. O Serviço Social apropria-se, principalmente, das seguintes perspectivas teóricas: positivismo, fenomenologia, materialismo dialético, as quais embasam a construção do conhecimento dessa disciplina. Por metodologia, entendemos um conjunto de procedimentos técnicos na realização da pesquisa, a sistematização dos dados e a forma de análise dos resultados.

Assim posto, propomo-nos, nesse momento, a apresentar uma das concepções de mundo, que embasam as pesquisas em Serviço Social, trazendo, em versão preliminar e em traços gerais, os principais apontamentos da concepção dialética marxiana, ou seja, descrevendo como esse modo de apreender a realidade social desenvolveu-se no percurso histórico da humanidade. Para isso, vamos seguir os caminhos apontados por Leandro Konder, Chasin, Lukács, e retomaremos, principalmente, algumas passagens das obras de Marx.

$\mathrm{Na}$ Grécia Antiga a dialética era concebida como a arte do diálogo; na concepção moderna ela é entendida como o modo de pensar as contradições da realidade social e de compreendê-las como essencialmente contraditórias e em permanente transformação. Da arte do diálogo ao modo de 'pensar as contradições da realidade', a dialética foi interpretada por diversos pensadores na história da humanidade. Apresentaremos, brevemente, alguns desses pensadores que contribuíram com fragmentos de suas obras à dialética.

Aristóteles considerava Zênon de Eléia (aprox. 490430 a.C.) o fundador da dialética, mas foi Heráclito de

Éfeso (aprox. 535-470 a.C.) o pensador dialético mais radical. Nos fragmentos deixados por Heráclito, podese ler que tudo existe em constante mudança, que o conflito é o pai e o rei de todas as coisas. Na Antigüidade, Heráclito não foi compreendido, pois consideraram seu modo de pensar confuso. $\mathrm{O}$ pensamento predominante na Antigüidade era o metafísico, tendo Parmênides de Eléia (aprox. 540-470 a.C.) anunciado que "a essência profunda do ser era imutável e a mudança era um fenômeno superficial", o que predominou na sua época, conforme citado por Konder (1981, p. 10).

Aristóteles (370-22 a.C.), descrito por Marx como o maior pensador da Antigüidade, ou o melhor, "um pensador portentoso", reintroduziu princípios dialéticos em explicações dominadas pelo modo de pensar metafísico. Aristóteles (apud Marx, 1983, p. 63) indagou-se sobre as relações de troca das mercadorias na sua sociedade da seguinte maneira:

Porque todo o bem pode servir para dois usos [...] Um é próprio à coisa em si, mas não o outro; assim, uma sandália pode servir como calçado, mas também como objeto de troca. Trata-se, nos dois casos, de valores de uso da sandália, porque aquele que troca a sandália por aquilo de que necessita, alimentos, por exemplo, serve-se também da sandália. Contudo, não é este o seu uso natural. Pois 
que a sandália não foi feita para troca. $\mathrm{O}$ mesmo se passa com os outros bens.

Ou seja, podemos permutar coisas diferentes pelo mesmo valor, mas que não coincidam na sua essência. Aristóteles, na frase citada, remete-se à realidade social das relações de troca da Antiguidade. Ele faz o seguinte questionamento: como podemos permutar coisas diferentes pelo mesmo valor, mas que não coincidem na sua essência? Aristóteles não obteve sucesso na solução desta indagação, dada a estrutura social composta por homens livres e escravos, o que não proporcionava a divisão do trabalho.

Assim, podemos dizer que a metafísica prevaleceu sobre a dialética nas explicações sobre as relações sociais, sendo que a dialética sempre esteve e estará presente na 'prática social'.

Na Idade Média a dialética é expulsa da filosofia com o imperialismo da teologia. Nessa época, os homens reproduziam-se, em sua maioria, nos campos e a explicação dos fenômenos da humanidade era contemplada pela concepção teológica. Na decadência do feudalismo e, conseqüentemente, com o surgimento das cidades, constituídas pelos antigos burgos, a racionalidade é exigida para as explicações dos fenômenos da humanidade (KONDER, 1981).

No Renascimento, o teocentrismo cede lugar ao antropocentrismo, a dialética sai dos subterrâneos, provocando o ressurgimento da arte e da literatura, seguido do desenvolvimento das ciências naturais. Nesse contexto, diversos pensadores indagam-se sobre as condições objetivas da humanidade. Giordano Bruno (1548-1606), que exaltou o homo faber, o homem capaz de dominar as forças naturais e de modificar criadoramente o mundo. Montaigne (1533-1592), para quem "Todas as coisas estão sujeitas a passar de uma mudança a outra, a razão, buscando nelas uma substância real, só pode frustrar-se, pois nada pode apreender de permanente, já que tudo ou está começando a ser - e absolutamente ainda não é - ou então já está começando a morrer antes de ter sido". Galileu Galilei (1564-642) e René Descartes (15961642), pela descoberta de que a condição natural dos corpos era o movimento e não o estado de repouso. Pascal (1623-654), que reconheceu o caráter instável, dinâmico e contraditório da condição humana. E Giambattista Vico (1680-1744), para quem o homem não podia conhecer a natureza, que é feita por Deus, mas sustentava que o homem podia conhecer sua própria história, pois é criada por ele (KONDER, 1981).

No iluminismo, movimento de idéias precedente à Revolução Francesa, os pensadores perceberam que os resquícios do feudalismo deveriam desaparecer, para dar lugar a um mundo novo, mais racional. A Revolução Francesa permitiu aos filósofos uma compreensão mais concreta da dinâmica das transfor- mações sociais. Dentre os pensadores dessa época destacamos Denis Diderot (1713-1784), que compreendeu o indivíduo como um ser condicionado por um movimento mais amplo, pelas mudanças da sociedade em que vivia. Jean-Jacques Rousseau (1712-1778), para quem os homens nasciam livres, mas a organização da sociedade lhes tolhia o exercício da liberdade natural. A observação da estrutura social do seu tempo e suas contradições, permitiu a Rousseau perceber os exageros dos conflitos de interesses entre os indivíduos, a má distribuição da propriedade, o poder concentrado em poucas mãos, e as pessoas escravizadas ao seu próprio egoísmo (KONDER, 1981).

A passagem do século 18 ao século19 marca transformações de radical impacto na base material da sociabilidade e, com isso, despontam reivindicações de uma maior racionalidade à explicação dos fenômenos naturais e, principalmente, dos sociais. Nesse período surgem grandes pensadores, que vão subsidiar o pensamento social moderno. O primeiro, Emanuel Kant (1724-1804), percebeu que a consciência humana não se limita a registrar passivamente as impressões provenientes do mundo exterior, mas interfere ativamente na realidade. Ele fez a seguinte pergunta: O que é o conhecimento? O segundo, Georg Wilhelm Friedrich Hegel (1770-1831), afirmava que a contradição era um princípio básico que não podia ser suprimido nem da consciência do sujeito, nem da realidade objetiva. Para Hegel, a questão central da filosofia era a questão do ser em si mesmo, e não do conhecimento. Hegel percebe que o trabalho é a mola que impulsiona o desenvolvimento do homem; é no trabalho que o homem produz a si mesmo; é o núcleo a partir do qual podem ser compreendidas as formas complicadas da atividade criadora do ser social. Hegel subordinava os movimentos da realidade material à lógica de um princípio que ele chamava de Idéia Absoluta, princípio inevitavelmente nebuloso, onde os movimentos da realidade material eram, frequientemente, descritos pelo filósofo de maneira vaga.

No século 19, Karl Marx (1818-1883) afirmou que a dialética hegeliana estava de cabeça para baixo; decidiu, então, colocá-la sobre seus pés. Para Marx, Hegel deu importância demais ao trabalho intelectual, sem enxergar o trabalho físico, material, que degenera e aliena o indivíduo. Essa concepção abstra$\mathrm{ta}^{11}$ do trabalho levava Hegel a fixar a atenção exclusivamente na criatividade, ignorando as deformações a que o trabalho é submetido em sua realização material e social na sociabilidade capitalista. $\mathrm{Na}$ dialética marxiana, "o conhecimento é totalizante e a atividade humana, em geral, é um processo de totalização, que nunca alcança uma etapa definitiva e acabada" (KONDER, 1981, p. 43 ).

Para explicitação da dialética marxiana recorreremos à citação de Marx (2002, p. 28-29): 
Meu método dialético, por seu fundamento, difere do método hegeliano, sendo a ele inteiramente oposto. Para Hegel, o processo do pensamento que ele transforma em sujeito autônomo sob o nome de idéia - é o criador do real, e o real é apenas sua manifestação externa. Para mim, ao contrário, o ideal não é mais do que o material transposto para a cabeça do ser humano e por ele interpretado. [...] A mistificação por que a dialética passa nas mãos de Hegel não o impediu de ser o primeiro a apresentar suas formas gerais de movimento, de maneira ampla e consciente. Em Hegel, a dialética está de cabeça para baixo. É necessário pô-la de cabeça para cima, a fim de descobrir a substância racional dentro do invólucro místico.

Marx constrói um método que emerge da realidade social, o qual procura investigar a conexão íntima do movimento real, pois, na perspectiva ontológica (marxiana), só é possível apreender o real por meio de construções de categorias, ou seja, de determinadas apropriações do objeto de estudo ${ }^{12}$. Para Marx (2002, p. 21),

A investigação tem de apoderar-se da matéria, em seus pormenores, de analisar suas diferentes formas de desenvolvimento e de perquirir a conexão íntima que há entre elas. Só depois de concluído esse trabalho é que se pode descrever, adequadamente, o movimento real. Se isto se consegue, ficará espelhada, no plano ideal, a vida da realidade pesquisada [...].

O método de apreensão da realidade é uma profunda relação entre subjetividade e objetividade. A realidade objetiva, por ser produto da práxis humana, é subjetividade objetivada, ao passo que a subjetividade, pelo mesmo motivo, é a realidade objetiva que adquiriu forma subjetiva. Observe a afirmação de Marx (2005, p. 38-39, grifo nosso): "O trabalho filosófico não consiste em que o pensamento se concretize nas determinações políticas, mas em que as determinações políticas existentes se volatilizem no pensamento abstrato. 'O momento filosófico não é a lógica da coisa, mas a coisa da lógica"”.

Lukács (1970, p. 35) destaca que "[...] o método dialético tende a conhecer todos os setores do ser e da consciência como um processo histórico movido por contradições [...]". Na apreensão do real, devemos exercitar a dialeticidade entre as categorias ${ }^{13}$ : a universalidade, essência dos fenômenos (concretode-pensamento); a particularidade, mediações (determinação histórica) e a singularidade, imediaticidade do real (fenômeno dado).

De acordo com Lukács (1970, p. 81),

A ciência autêntica extrai da própria realidade as condições estruturais e as suas transformações his- tóricas e, se formula leis, estas abraçam a universalidade do processo, mas de um modo tal que deste conjunto de leis pode-se sempre retornar - ainda que freqüentemente através de muitas mediações aos fatos singulares da vida. É precisamente esta a dialética concretamente realizada de universal, particular e singular.

A preocupação em percorrer as múltiplas determinações do movimento real (objeto) é o núcleo norteador do pensamento marxiano. Pois, tudo o que aparece e se move na reflexão - construção do conhecimento - é a substância e a lógica do objeto analisado, que é reproduzido pelo cérebro em sua gênese e necessidade, historicamente engendradas e desenvolvidas. A identificação da dialeticidade como lógica do real e os movimentos das categorias são apreendidos enquanto formas de existência, que os concretos de pensamentos reproduzem. "Razão pela qual a dialética só é possível de descobrimento, jamais de aplicação" (CHASIN, 1996, p. 420).

Entretanto, para atender esse pressuposto teóricometodológico, o pesquisador parte da imediaticidade (objeto de estudo) - que é síntese das determinações sociais, políticas, econômicas, ideológicas - para, na construção de categorias (mediações), aproximar-se de uma compreensão que contemple as múltiplas determinações do objeto, na sua totalidade.

Assim, pensamos o concreto ${ }^{14}$ através de construções abstratas que apropriam o real pelo pensamento, e buscam apreender o movimento real enquanto processo dinâmico e contraditório, mas não como um movimento rígido preestabelecido ${ }^{15}$. Esse método de apreensão da realidade social não se atém a procedimentos de raciocínio apologéticos ou contemplativos, mas tem como premissa a construção de um saber que põe em primeiro momento as condições sociais reais do homem e suas formas de existência. Observe a seguinte passagem de Marx (1983, p. 24): "O modo de produção de vida material condiciona o desenvolvimento da vida social, política e intelectual em geral. Não é a consciência dos homens que determina o seu ser, é o seu ser social que, inversamente, determina a sua consciência". No entanto, estamos diante de uma perspectiva teóricometodológica que não só apresenta os caminhos à apreensão do mundo dos homens na sua concretude histórica e pelas suas bases objetivas, mas nos apresenta os passos possíveis para a superação da lógica do capital pela lógica onímoda do trabalho, que necessariamente passará pela transformação radical e que, por fim, reivindica uma sociedade verdadeiramente humana. $\mathrm{O}$ conhecimento pelo conhecimento defendido pela concepção burguesa de ciências sociais, torna-se um procedimento escolástico que, portanto, fica aquém da realidade social, é pensamento pensando pensamento e não a realidade social, a qual 
no momento atual, carece de interpretações seguidas de ações efetivas do homem. Agora, mais do que nunca, o seguinte enunciado é necessário: "Os filósofos se limitaram a 'interpretar' o mundo de diferentes maneiras; o que importa é "transformá-lo"" (MARX; ENGELS, 1999, p. 14, grifo nosso).

\section{Considerações finais}

Abordar a temática da concepção burguesa de ciências sociais, pesquisa, produção do conhecimento em Serviço Social e perspectiva ontológica é de suma importância, pois deparamos com um crescimento gigantesco de materiais de pesquisa e, concomitantemente, de profissionais que são titulados por tais produções.

Ao longo do texto apresentado, objetivamos pôr em debate algumas preocupações, dentre as quais a concepção burguesa de ciências sociais; a produção acadêmica que visualiza somente os títulos; o compromisso do pesquisador em Serviço Social; uma perspectiva teórico-metodológica, que denominamos 'ontológica', por buscar nas obras de Marx e seus principais seguidores os fundamentos essenciais para análise e apreensão da realidade social.

Concluímos reforçando alguns elementos, disseminados durante esta exposição. Sabemos que desde os programas de pós-graduação, passando pelas agências de fomento e avaliação de pesquisas, os horizontes estão cravados de acordo com os ditames da produção quantitativa do conhecimento, que é a radicalização da ciência burguesa.

Quando o aluno ingressa na pós-graduação, é avaliado pela quantidade de artigos publicados, desconsiderando-se a qualidade científica das suas produções teóricas.

O modo como a 'Universidade Moderna' relaciona-se com a pesquisa e a produção do conhecimento é comprometedor, pois, ambas, como já destacamos anteriormente, passam a ser, para alguns 'acadêmicos', meros mecanismos para conseguirem os denominados 'títulos'. Cremos que, dessa maneira, o conhecimento tende a se tornar mais uma mercadoria. Os que o produzem devem tomar o cuidado para não se tornarem 'intelectuais' estranhados com o que fazem, nem legitimar a concepção burguesa de ciência. Devemos nos alertar para não fazermos da Universidade uma 'feira de opiniões', em que são mercadejados os 'achismos'.

Outro ponto de suma importância, que destacamos, é o compromisso do pesquisador em Serviço Social. As diretrizes curriculares do curso de Serviço Social situam a profissão inserida no conjunto das relações de produção e reprodução da vida social, sendo de caráter interventiva e que atua no âmbito da questão social. Essa aproximação da profissão com a realidade social não é simplesmente um epifenômeno. Por tal questão, acreditamos que os objetos de estudos do Serviço Social, necessariamente, partem de uma realidade concreta que é determinada socialmente, ou seja, estabelece as suas mediações numa sociedade que se produz e reproduz por meio de suas contradições inconciliáveis. Portanto, apontar uma referência teóricometodológica que reconhece a realidade social como o ponto de partida das análises científicas e, conseqüentemente, da produção do conhecimento, aproxima-nos de respostas concretas diante da mundaneidade social.

\section{Referências}

AMMANN, S. B. A produção científica do Serviço Social no Brasil. Serviço Social \& Sociedade, São Paulo: Cortez, n. 14, p. 145-154, 1984.

CHASIN, J. Marx - estatuto ontológico e resolução metodológica. In: TEIXEIRA, F. Pensando com Marx. São Paulo: Ensaio, 1996. p. 335-537.

DEMO, P. Pesquisa: princípio científico e educativo. São Paulo: Cortez, 1997a.

Conhecimento moderno: sobre ética e intervenção do conhecimento. Petrópolis: Vozes, 1997b.

IAMAMOTO, M. V.; CARVALHO, R. Relações sociais e Serviço Social no Brasil. São Paulo: Cortez, 1998.

KAMEYAMA, N. A trajetória da produção de conhecimentos em Serviço Social: alguns avanços e tendências (1975-1997). Cadernos ABESS, São Paulo: Cortez, n. 8, p. 33-76, 1998.

KONDER, L. O que é dialética. São Paulo: Brasiliense, 1981.

LUKÁCS, G. Introdução a uma estética marxista - sobre a particularidade como categoria da estética. Tradução de Carlos Nelson Coutinho e Leandro Konder. Rio de Janeiro: Civilização Brasileira, 1970.

Ontologia do ser social: os princípios ontológicos fundamentais de Marx. Tradução de Carlos Nelson Coutinho. São Paulo: Livraria e Edit. Ciências Humanas, 1979.

. Marxismo e questões de método na ciência social. In: PAULO NETTO, J. (Org.); FERNANDES, F. (Coord). Lukács, Sociologia. São Paulo: Ática, 1981. (Coleção Grandes Cientistas Sociais). 
MARX, K. Contribuição à crítica da economia política. Tradução de Maria Helena Barreiro Alves. São Paulo: Martins Fontes, 1983.

. Manuscritos econômico-filosóficos. Lisboa: Edições 70, 1993.

.; ENGELS, F. A ideologia alemã. 11. ed., São Paulo: Hucitec, 1999.

O Capital: crítica da economia política. Tradução de Reginaldo Sant'Anna. Rio de Janeiro: Civilização Brasileira, 2002. (Livro 1, Volume I).

Crítica da filosofia do direito de Hegel. São Paulo: Boitempo Editorial, 2005.

MÉSZÁROS, I. O poder da ideologia. São Paulo: Boitempo Editorial, 2004.

PÁDUA, E. M. M. Metodologia da pesquisa: abordagem teórica-prática. Campinas: Papirus, 2004.

PAULO NETO, J. Crise do socialismo e ofensiva neoliberal. São Paulo: Cortez, 2001a.

$2001 \mathrm{~b}$.

Ditadura e Serviço Social. São Paulo: Cortez,

SETUBAL, A. Pesquisa em Serviço Social: utopia e realidade. São Paulo: Cortez, 1995.

\section{Notas}

1 Utilizamos o termo 'Universidade Moderna' entre aspas por entender que na atualidade tal Instituição e os seus representantes ditos 'intelectuais' ou 'acadêmicos' não estão respondendo com a radicalidade, seriedade eimportância que ela representa enquanto espaço de resistência cultural e crítica.

2 Observe a argumentação de Lukács (1981, p. 23): “Iniciemos pela nova ciência da época da decadência: a sociologia. Ela surge como ciência autônoma porque os ideólogos burgueses pretendem estudar as leis e a história do desenvolvimento social 'separando-as daeconomia'. A tendência objetivamente apologética desta orientação não deixa lugar a dúvidas. Após o surgimento da economia marxista, seria impossível ignorar a luta de classes como fato fundamental do desenvolvimento social, sempre que as relações sociais fossem estudadas a partir da economia. Para fugir desta necessidade, surgiu a sociologia como ciência autônoma; quanto mais ela elaborou seu método, tão mais formalista se tornou, tanto mais substituiu, à investigação das reais conexões causais na vida social, análises formalistas e vazios raciocínios analógicos [...] Paralelamente a este processo, ocorre na economia uma fuga da análise geral de produção e reprodução e uma fixação na análise dos fenômenos superficiais da circulação, tomados isoladamente. [...] Assim como a sociologia deveria constituir uma 'ciência normativa', sem conteúdo históricoe econômico, do mesmo modo a História deveria limitar-se à exposição da 'unicidade' do decurso histórico, sem levar em consideração as leis da vida social".

3 Temos como referência nesse momento de discussão sobre a questão social a concepção de Iamamoto e Carvalho (1998, p. 77): “A 'questão social' não é senão as expressões do processo de formação e desenvolvimento da classe operária e de seu ingresso no cenário político da sociedade, exigindo seu reconhecimento como classe por parte do empresariado e doEstado.Éa manifestação, no cotidiano da vida social, da contradição entre o proletariado e a burguesia, a qual passa a exigir outros tipos de intervenção, mas além da caridade e repressão".

4 "Dependendo da identificação [do pesquisador] com setores da sociedade, e essa não é uma situação específica do Serviço Social, o conhecimento ou pode ser favorável e reafirmar o poder instituído, ou pode ser desvendador das situações conflituosas existentes nas relações sociais, muitas vezes camufladas pelas políticas de governo concretizadas pelos programas assistenciais"(SETUBAL, 1995, p. 46).

5 "Sem dúvida, a arma da crítica não pode substituir a crítica das armas; a força material só será derrubada pela força material; mas ateoriaem si torna-se tambémumaforça material quando se apodera das massas. A teoria é capaz de se apossar das massas ao demonstrar-se ad hominem, e demonstra-se ad hominem logo que se torna radical. Ser radical é agarrar as coisas pela raiz. Mas, para ohomem, a raizéo próprio homem" (MARX, 1993,p. 86).

6 "Diante da amplitude e da complexidade das questões que envolvem a definição de conhecimentoé que o Serviço Social vê-se obrigado a refletir sobre a sua própria natureza. Éentão a partir do deslocamento de uma programação desenvolvida pelaAssociação Brasileira de Ensino no Serviço Social, nestas duas últimas décadas, principalmente nos primeiros anos de 1980, que é travado no interior do Serviço Social um debate polêmico sobre a construção do conhecimento"(SETUBAL, 1995,p.31).

7 Fonte: $\langle$ www.cnpq.br $\rangle$. Acessoem: 21 de novembro de 2005.

8 "Este relevo tem reconhecimento institucional: credibilizandose como interlocutor das ciências sociais e desenvolvendose no plano da pesquisa e da investigação, o Serviço Social consagra-se junto a agências oficiais de financiamento que apóiam a 'produção de conhecimento' " (PAULO NETTO, 2001b, p. 133).

9 "Esta constituição - que supõe, entre outros dados, a diferenciação entre segmentos profissionais alocados preferencialmente à prática e segmentos alocados 
especialmente ao trabalho investigativo - tem sido equivocadamente identificado a uma ruptura teoricista com a prática profissional; como sabem todos aqueles que têm alguma familiaridade com a reflexão sistemática, ela é a condição mesma para a criação dos requisitos para a compreensão crítica da prática profissional"'(PAULONETTO, 2001b, p. 136).

10 'A A busca de uma explicação 'verdadeira' para as relações que ocorrem entre os fatos, quer naturais, quer sociais, passa, dentro da chamada teoria do conhecimento, pela discussão do método"(PÁDUA, 2004,p. 10).

11 Segundo Marx, “[...] o ponto de partida de Hegel é o da economia política. Concebe o 'trabalho' como a 'essência' confirmativa do homem; considera apenas o lado positivo do trabalho, não o seu aspecto negativo. O trabalho é o 'tornar-se-para-si do homem' no interior da 'alienação' ou como homem alienado. Oúnico trabalho que Hegel entende e reconhece é o trabalho ‘intelectual abstrato'. Assim, o que acima de tudo constitui a essência da filosofia, a 'alienação do homem que se conhece a si mesmo' ou a ciência 'alienada' que a si mesma se pensa, considera-o Hegel como a sua essência. Por conseguinte, consegue combinar os elementos individuais da filosofia anterior e apresentar a sua filosofia como 'a' filosofia. O que os outros filósofos fizeram-istoé, conceber os elementos individuais da natureza e a vida humana como momentos da autoconsciência e, sem dúvida, da autoconsciência abstrata - 'conhece'-o Hegel através da 'prática' da filosofia; portanto, a sua ciência é absoluta" (MARX, 1993,p. 246).

12 "Do mesmo modo que em toda a ciência histórica ou social em geral, é preciso nunca esquecer, a propósito da evolução das categorias econômicas, que o objeto, neste caso a sociedade burguesa moderna, é dado, tanto na realidade como no cérebro; não esquecer que as 'categorias exprimem portanto formas de existência, condições de existência determinadas', muitas vezes simples aspectos particulares desta sociedade determinada, deste objeto, e que, por conseguinte, esta sociedade de maneira nenhuma começa a existir, inclusive doponto de vista científico, somente a partir do momento em que ela está em questão" (MARX, 1983,p. 224).

13 "Para a consciência-e a consciência filosófica considera que o pensamento que concebe constitui o homem real e, por conseguinte, o mundo só é real quando concedido - para a consciência, portanto, o movimento das categorias surge como ato de produção-que recebe um simples impulso do exterior, o que é lamentado - cujo resultado é o mundo; e isto (mas trata-se ainda de uma tautologia) é exato na medida em que a totalidade concreta enquanto totalidade-de-pensamento, enquanto concreto-de-pensamento, é de fato um produto do pensamento, da atividade de conceber; ele nãoé pois de forma alguma o produto do conceito que engendra a si próprio, que passa exterior e superiormente à observação imediata e à representação, mas um produto da elaboração de conceitos a partir da observação imediata e da representação. O todo, na forma em que aparece no espírito como todo-de-pensamento, é de fato um produto do cérebro pensante, que se apropria do mundo do único modo que lhe é possível, de um modo que difere da apropriação desse mundo pela arte, pela religião, pelo espírito prático. Antes como depois, o objeto real conserva a sua independência fora do espírito; e isso durante o tempo em que espírito tiver uma atividade meramente especulativa, meramente teórica. Por conseqüência, também no emprego do método teórico é necessário que o objeto, a sociedade, esteja constantemente presente no espírito como dado primeiro" (MARX, 1983,p.219).

14 Segundo Marx (1982, p. 218-219), "O Concreto é concreto por ser a síntese de múltiplas determinações, logo, unidade da diversidade. É por isso que ele é para o pensamento um processo de síntese, um resultado, e não um ponto de partida, apesar de ser o verdadeiro ponto de partida e portanto igualmente o ponto de partida da observação imediata e da representação".

15 “A perspectiva teórico-metodológica instaurada pela obra marxiana - com seu cariz ontológico, sua radicalidade histórico-crítica e seus procedimentos categorial-articulados - é aquela que permite, arrancando dos 'fatos' objetivados na empiria da vida social na ordem burguesa, determinar os processos que os engendram e as totalidades concretas que constituem e em que se movem. Esta perspectiva é a que propicia, na dissolução da pseudo-objetividade necessária da superfície da vida capitalista, apreender e desvelar os modos de ser e de reproduzir-se do ser social na ordem burguesa"(PAULONETTO, 2001a, p. 37).

\section{Ricardo Lara}

Assistente Social, Mestre e Doutorando em Serviço Social pelo Programa de Pós-Graduação em Serviço Social da Universidade Estadual Paulista (UNESP) Professor do Curso de Serviço Social da Universidade de Uberaba (UNIUBE) e do Centro Universitário da Fundação Educacional Guaxupé (UNIFEG) UNIUBE:

Campus Rodoviária

Av. Barão do Rio Branco, 770, São Benedito Uberaba - Minas Gerais

CEP: $38020-300$ 